\title{
A práxis comunicacional e a construção de um saber emancipatório: um diálogo entre Freire, Kaplún e Martín-Barbero
}

\author{
Rosane Rosa* \\ Manuela Ilha Silva**
}

Resumo: $\mathrm{O}$ fenômeno da midiatização alcança os diferentes espaços sociais, dentre eles o ambiente escolar. Assim, a relação mídia-escola e as aproximações entre a prática comunicacional, a produção de sentidos e o processo de aprendizagem são o foco do presente trabalho. Através da construção de aproximações entre os campos da Educação e Comunicação, é possível apontar as relações e as responsabilidades de ambas na construção do conhecimento. Também, ao observar sob a ótica das mediações, é possível ver as conexões entre a realidade escolar e as representações culturais. Nessa interface, vê-se como a Educomunicação é escopo à formação cidadã, plena e emancipatória dos jovens.

Palavras-chave: Comunicação; Educação; Mediações; Educomunicação.

Resumem: El fenómeno de la mediatizacíon llega a diferentes espacios sociales, incluyendo el entorno escolar. Por lo tanto, la relación de los medios de comunicación con la escuela y los vínculos entre la práctica de la comunicación, su producción y circulación de significados y el proceso de el aprendizaje son el foco de este trabajo. A través de la construcción de enfoques entre los campos de la Educación y la Comunicación, es posible identificar las relaciones y responsabilidades tanto de la construcción del conocimiento. Además, cuando se mira desde la perspectiva de las mediaciones, se puede ver las conexiones entre la realidad escolar y las representaciones culturales. En esta interfaz, se ve como Educomunicación es margen para la formación ciudadana y la emancipación completa de jóvenes.

Palabras clave: Comunicación; Educación; Mediaciones; Educomunicación;

Abstract: The phenomenon of mediatization reaches different social spaces, among them the school environment. Then, the relation media-school and the links between the practice communication of production and circulation of meanings and the process of learning are the focus of this research. By building similarities between the fields of Education and Communication, is pos- 
A práxis comunicacional e a construção de um saber emancipatório...

sible pointing out the relations and responsibilities of both the construction of knowledge. Also, when looking from the perspective of mediations, is possible see the connections between the school reality and the cultural representations. In this interface, it is seen as Educommunication is scope for citizen training, full and emancipated youth.

Keywords: Communication; Education; Mediation; Educomunication

\section{Introdução}

A escola como instituição educativa, social e política é abalada ou questionada na sua estrutura tradicional pela relação com a Comunicação Midiática, porque em uma sociedade midiatizada, as práticas sociais são mediadas e relacionam-se diretamente com os valores simbólicos e representações sugeridas pelos meios. A escola, como espaço de elaboração do processo de aprendizado, torna-se, então, palco para o exercício de um pensar e um agir críticos. Contudo, o processo de construção de conhecimento já não se dá, exclusivamente, no ambiente escolar.

Informalmente, outros espaços e fatores coadunam com a construção de conhecimentos - a mídia é o principal deles. Trata-se de espaços e conhecimentos complementares. Além disso, mídia e escola, tem um importante papel socializador e de construção de valores, representações e identidades. "A escola e a mídia desempenham o papel de guardiãs e difusoras de uma espécie de síntese de valores hegemônicos que formam o consenso indispensável à sociedade" (BELLONI, 2009, p. 33). Todavia, a recepção de tais mensagens ainda é carente de posturas críticas, o que é campo fértil para experiências em Educomunicação. "Busca-se formar o receptor crítico, ativo, inteligente e capaz de distanciar-se da mensagem midiática e exercer sobre ela seu poder de análise e crítica” (p.45).

Os diferentes espaços sociais em que o homem transita o fazem construir conhecimento na relação com os demais sujeitos e com o mundo. A mídia não foge a tal regra, e é espaço central de oferta de valores e produtos simbólicos que estão arraigados à sociedade. O poder que a mídia goza, ao agendar, selecionar e apontar preferências na realidade social evidencia a necessidade de uma ação crítica e reflexiva sobre a mesma no ambiente escolar.

O caráter polivalente do campo da Comunicação permite estudos 
de interface com outras áreas do conhecimento, sendo uma delas a Educação, como é o caso do estudo aqui proposto. Freire (1977, p.69) aponta essa forte aproximação, vendo a Educação como sinônimo de Comunicação, ambas como práticas dialógicas e encontro de sujeitos. Dessa relação, o sujeito cresce e desenvolve-se, ratificando o papel da escola de oferecer "condição à participação, como incubadora da cidadania, como processo formativo" (DEMO, 2009, p.52).

Assim, esse este artigo propõe-se a refletir sobre questões pertinentes a convergência educomunicativa, ou seja, as interfaces entre Comunicação e Educação. Para tanto foram descritos argumentos de estudiosos clássicos como Freire e Kaplun, mas também de pesquisadores contemporâneos como Martín-Barbero, Peruzzo e Demo, entre outros.

\section{Entre Práticas Educacionais Anti-dialógicas e Dialógicas}

Esse modelo antidialógico foi objeto de questionamento por outra corrente, que passou a dar atenção aos efeitos do processo educativo. Em uma primeira análise, há pontos que coadunam com a educação libertadora pensada por Freire (1976) e com a proposta de Kaplún (1985). Todavia, ele se distingue pelo caráter manipulador. $\mathrm{O}$ pesquisador uruguaio lembra que tanto a Educação como a Comunicação foram pensadas, à época, para alcançar índices de produtividade.

Segundo Kaplún (1985, p. 9), nesta proposta, “já não se trata [...] só de informar e dar conhecimentos; mas, sobretudo, de convencer, de manipular, de condicionar o indivíduo, para que adote a nova postura”. O hábito torna-se questão central na Educação, assim como o sistema de recompensas. As ações são automáticas e não reflexivas, e tem motivações ligadas diretamente ao prêmio final.

Kaplún (1997, p. 4) finaliza apontando que este modelo trouxe diferenças insignificantes, visto que, "em suma, substituem uma imposição por outra imposição”. O educando é tolhido da ação reflexiva, e acaba por acostumar-se a depender de outros para suas ações e para a tomada de decisões. Isso acaba por fomentar a perda da identidade cultural e a manutenção do status quo do educador.

As ações de desenvolvimento propostas sob a égide da modernização da América Latina, em meados dos anos 1950 e 1960, exemplificam a ação antidialógica relacionada à cultura como capaz de tolher, reprimir e 
alienar os sujeitos, transformando-os em massa única e indistinguível. No entanto, ela possui um movimento contrário. Tal posição, que se opõe à falta de diálogo e dominação da ação antidialógica, mostra quatro pontos de alcance. Através deles, há estímulo à comunicação, à valorização cultural e à emancipação dos sujeitos, conforme suas singularidades.

Nessa perspectiva, o mundo é espaço de convivência e partilha entre sujeitos multiculturais, que são agentes de transformação e parceiros em ações colaborativas. Tal corrente alicerça a Pedagogia do Oprimido, de cunho libertador, proposta por Freire (2005) para uma ação pedagógica diferenciada, calcada no sujeito, em sua bagagem cultural e suas relações com o mundo.

A Co-laboração é a primeira resposta da ação dialógica, sendo o encontro entre os sujeitos que antes ocupavam as posições antagônicas de opressor e oprimido. Aqui, ambos permanecem em lugares equivalentes, e convergem para a interação. Há uma aproximação para a compreensão do mundo, isto é, para que próximos e de forma colaborativa, possam re-construir a realidade onde estão inseridos. O fundamental para a co-laboração é o diálogo - é na comunicação que acontece o processo colaborativo.

A União é a segunda face da ação dialógica, e comporta-se como resposta à ação opressora da divisão. Ela busca estabelecer pontos de comunicação entre diferentes grupos culturais, a fim de aproximá-los e torná-los coesos em lutas de interesses comuns. Tal aproximação é resultado de uma ação cultural, capaz de esclarecer e organizar os grupos divididos em um grande e coeso grupo, capaz de emancipar-se. Para Freire (2005, p. 200), "o objetivo da ação dialógica está, pelo contrário, em proporcionar que os oprimidos, reconhecendo o porquê e o como da sua 'aderência', exerçam um ato de adesão à práxis verdadeira de transformação da realidade injusta”.

Ao unir-se com outras pessoas, o sujeito é capaz de compreender que, na opressão, ele era um homem proibido de "estar sendo", vivendo à semelhança de seu opressor. Freire (2005, p. 201) complementa "para que os oprimidos se unam entre si, é preciso que cortem o cordão umbilical, de caráter mágico e mítico, através do qual se encontram ligados ao mundo da opressão". O descobrimento de si mesmo é um primeiro momento, resultante de uma ação cultural, onde cada um, ao problematizar sua própria existência, é capaz de ver-se um ser singular, insubordinado e capaz de assumir-se como agente transformador do mundo, quebrando o paradigma de "quase coisas" a qual estão subordinados.

$\mathrm{Na}$ ação dialógica, ao contrário da manipulação, encontra-se a Organização. Através da articulação e da mobilização de grupos, é possível 
promover a "pronúncia" reflexiva do mundo, em um processo de aprendizagem. Para tal articulação, uma liderança ou um mediador se faz necessário, todavia, sem autoritarismos e com respeito. Assim, juntos compreendem, apreendem e instauram "a transformação da realidade que os mediatiza" (FREIRE, 2005, p. 207).

A última expressão da ação dialógica é a Síntese Cultural. Através dessa ação cultural, é viável pensar em mudanças de estruturas sociais. O objetivo de uma ação cultural com caráter de síntese é a possibilidade de contornar contradições presentes na estrutura sócio-cultural, promovendo a libertação do indivíduo. A ação que é dialógica aponta a superação de posturas e culturas alienadas e alienantes. Sua atuação é histórica, resultando em uma práxis capaz de integrar e promover a convivência entre diferentes expressões culturais. Essas diferenças deixam de ser motivos de conflitos, e passam a ser subsídios para fusões que resultam em novas expressões culturais.

Nestas proposições de ação dialógica, a Comunicação surge como pressuposto, visto que é através do diálogo que se organiza tal expressão na prática. Assim, constrói-se um espaço de trocas entre sujeitos que comungam um projeto em comum - a autonomia, em um processo com ares de revolução, ou dito de outra forma, de intervenção através de participação social e política a começar pelo ambiente educacional. Para Freire (1996, p. 154), "o sujeito que se abre ao mundo e aos outros inaugura com seu gesto a relação dialógica em que se confirma como inquietação e curiosidade, como inconclusão em permanente movimento na História”.

\section{Comunicação como Estímulo à Autonomia}

Entre os distintos conceitos de Comunicação, há um com significado genuíno e ratificador do seu papel como estratégia de sobrevivência humana. Comunicar é a prática do diálogo. Assim, a relação com o outro, em um processo dialógico, é o conceito mais inato para a Comunicação. Nesta relação, o sujeito também é capaz de aprender e construir conhecimento, em uma interação com o outro e também com o mundo (FREIRE, 2005).

Em outros contextos sociais e temporais, a escola era um dos principais detentores da tarefa de transmitir normas, valores, símbolos, crenças e elementos culturais para as novas gerações. Caracterizava-se como espaço 
de socialização, compartilhamento do patrimônio cultural e de conhecimentos, como também exercia fundamental papel para a construção de uma consciência e identidade cidadã.

Todavia, a sociedade atual compartilha com outras estruturas esta tarefa de construção do conhecimento social. Para Martín-Barbero (2006, p. 56), "a escola está deixando de ser o único lugar de legitimação do saber, já que há uma variedade de saberes que circulam por outros canais, difusos e descentralizados". A Comunicação midiática é um dos novos e principais espaços responsáveis pela construção de valores, e sua presença no cotidiano social exige que se dedique atenção para tal relação.

Nesse cenário de sociedade midiatizada, torna-se fundamental que, no ambiente escolar, o conceito e a prática comunicacional de natureza comercial e espetacularizada que predomina na grande mídia, sejam re-significadas a partir de experiências e expressões próprias, vindas de diferentes grupos culturais que lutam para assumir uma posição pró-ativa. Assim, os meios e a produção das mensagens podem tornar-se espaços de educação crítica e transformadora, e possibilitar, no caso escolar, que a comunidade torne-se "geradora e protagonista" (KAPLÚN, 1985) deste processo educomunicacional.

Tais resultados são possíveis devido a uma característica da sociedade contemporânea - a formação que perpassa diferentes experiências e mediações. Assim, também a Comunicação insere-se como espaço de reflexão e construção de saberes e da cultura. Martín-Barbero destaca que na atualidade, o conhecimento que é legitimado socialmente passa por muitos lugares. A mídia é um campo central de conhecimento, que, para o autor, passou "a ocupar um lugar estratégico na configuração dos novos modelos de sociedade" (2006, p. 53).

Essa reconfiguração contempla mudanças nos imaginários individuais e coletivos, e os padrões midiáticos tornam-se referenciais simbólicos, de valores e comportamentais. Para o autor (2006, p. 71), "as mídias de massa se transformaram em 'máquinas de produzir o presente', ou seja, acham-se dedicadas a fabricar esquecimento".

Diante dessa realidade, é fundamental educar para uma reflexão crítica na recepção das mensagens midiáticas, o que pode ser feito através dos próprios meios. Ao alisar e desconstruir a lógica dos meios de produção é possível releituras e apropriações das mensagens do cotidiano comunitário onde os sujeitos estão inseridos. Quando participa, o indivíduo é capaz de reorganizar a visão de si próprio, do outro e do mundo. Torna-se sujeito ativo, crítico e politizado dentro do processo comunicacional, o que é 
fundamental para passagem da "cultura de silêncio" (FREIRE, 2005) para cultura do diálogo e da participação.

A democratização na produção dos processos comunicacionais é capaz de levar seus participantes a uma experiência única de conhecimento e educação para a cidadania. Essa prática possibilitará a atuação destes sujeitos em contextos amplos, como por exemplo, os grêmios estudantis, a comunidade, as organizações sociais e os movimentos populares. São experiências de efetiva interação que estimulam a criticidade, a politicidade e novas posturas. Esse processo de participação cidadã frutifica em práticas educativas e na postura democrática (PERUZZO,1998, p. 300).

Essas experiências são importantes subsídios para o desenvolvimento de um sujeito com postura autônoma, emancipatória e cidadã. Esse processo, todavia, é gradual, pois implica em romper "silêncios", estimular novas falas, releituras e apropriações, progredindo conforme o ritmo dos próprios sujeitos. São eles os principais responsáveis por sua emancipação, o que acontece a partir de ações pró-ativas, capazes de fomentar sua participação. Parafraseando Martín-Barbero (2003, p. 25), pode-se dizer que a liberdade vai moldando a consciência, e o diálogo e a participação se interiorizaram até o ponto em que o emancipado deixa de ver no opressor sua referência de vida.

\section{Conexões entre Aprender e Comunicar}

As aproximações entre o processo de aprendizagem e a Comunicação são significativas, com intersecções que merecem reflexão. Ou seja, comunicar também é um processo de aprendizagem, visto que possui um caráter relacional, de aproximação entre sujeitos. A recíproca é verdadeira, sendo o processo de aprendizagem dependente do ato comunicacional. Através dessa relação interdependente, o educando desenvolve aptidão para incluir-se em uma sociedade, essencialmente, plural.

Nessa visão, "a educação é comunicação, é diálogo, na medida em que não é transferência do saber, mas um encontro de sujeitos interlocutores que buscam a significação dos significados" (FREIRE, 1977, p.69). O processo é rico em re-descobertas, em re-construções de conhecimentos e posturas de um sujeito singular e inserido no seu espaço social.

A Comunicação ainda convive com reflexos de um modelo que objetiva interferir no comportamento dos receptores. Os meios massivos 
de comunicação são o exemplo principal para Kaplún (1985, p. 12-14), assim como as campanhas publicitárias que abusam da persuasão e a propaganda política. Sem espaço para a crítica, o trabalho da comunicação acaba reduzindo-se a slogans, campanhas e palavras de ordem.

Nesse contexto, é importante que a escola transforme-se em espaço de diálogo e reflexão para a formação de um receptor criticamente ativo diante da realidade representada e enquadrada na cultura midiática. Segundo Freire (1976, p.96), "a educação é um ato de amor, por isso, um ato de coragem. Não pode temer o debate. A análise da realidade. Não pode fugir à discussão criadora, sob pena de ser uma farsa".

O diálogo é criador e fundamental para a participação ativa dos educandos no processo de ensino-aprendizagem, assim como estabelece o modelo educacional endógeno proposto por Kaplún (1985, p. 18), cuja ênfase é dada ao processo, ou na Educação Libertadora proposta por Freire (1976). Tal modelo, originário da América Latina, reflete uma ideia de educação como ação política, prática de diálogo e interrelação entre sujeitos e o mundo.

A Educação torna-se sinônimo de diálogo, e é através dele que os sujeitos envolvidos neste processo transformam-se em interlocutores, quebrando hierarquias e transformando o sistema de aprendizagem em "açãoreflexão-ação” (KAPLÚN, 1985, p. 19). Nesse processo educacional, que também é comunicativo, o sujeito cresce e emancipa-se através das relações que estabelece com os demais sujeitos e com o mundo.

Ao exercitar sua capacidade de raciocínio e crítica, o sujeito torna-se consciente de seu papel nos diferentes espaços de sociabilidade, como a escola, a família, a comunidade e mundo. Segundo Freire (1979, p. 67), "posto diante do mundo, o homem estabelece uma relação sujeito-objeto da qual nasce o conhecimento, que ele expressa por uma linguagem”. Assim, é na prática do diálogo e na relação com o mundo que o indivíduo torna-se um sujeito emancipado. Neste contexto, a educação também se transforma. Nas palavras de Martín-Barbero, "passa-se a uma educação-práxis, dialética nas palavras e ações, onde a palavra surge ao ritmo do esforço construtor da própria realidade e a ação reverte-se possibilitando uma palavra inédita, criadora" (2003, p. 43).

O conhecimento surge como fruto de uma prática que é ação e diálogo, assim como encontro entre sujeitos e momento de reflexão. Para Kaplún (1997, p.4), ao educar-se, o sujeito acaba por envolver-se em uma rede múltipla de interações sociais. Nesta relação, ele aprende (e comunica) através da sua própria cultura e saberes, inserindo-se em uma grande rede 
de interlocutores e formando verdadeiros "circuitos comunicativos". Sua natureza e sua realidade são problematizadas de forma crítica, e através da bagagem já construída por este sujeito em processo de ensino-aprendizagem, alicerça-se a reflexão necessária a emancipação social. O importante, para Freire (2005, p. 139) é que os indivíduos passam a sentir-se sujeitos, discutindo o seu pensar e sua própria visão de mundo.

Diante deste contexto, o pensamento envolvido na prática dialógica do "aprender" torna-se expressão comunicativa. A construção de conhecimentos baseia-se fundamentalmente na prática comunicacional, e é através dela que o indivíduo afirma-se como sujeito. $\mathrm{O}$ exercício da $\mathrm{Co}^{-}$ municação é o que possibilita a inserção da pessoa humana e inserida no mundo e na expressão da linguagem. As conexões necessárias ao diálogo e à reflexão são fomentadas através da ação comunicacional, indissociável quando a Educação tem caráter libertário. Conforme Freire (1977, p.67), é impossível romper a Comunicação, e "por isto, não é possível compreender o pensamento fora de sua dupla função: cognoscitiva e comunicativa”.

Comunicar e construir conhecimento são ações íntimas e próximas, dependentes, confluentes e únicas quando o processo dialógico se instaura. Para Martín-Barbero (2003, p. 31), "a comunicação é ruptura e ponte - é mediação". Assim, o homem cresce e adquire conhecimentos através da relação com o outro, mediado pela ação comunicativa. São mediações como essa que transformam o indivíduo em sujeito emancipado, visto que a pessoa não é capaz de educar-se a si mesma nem aos demais - todos aprendem juntos, com o mundo como espaço de aprendizado (Freire, 2005, p.78).

\section{Mediações no Processo de Apropriação de Sentidos}

Martín-Barbero (2001a) foca sua atenção para além dos meios. Para ele é necessário a observação das mediações e articulações entre "as práticas de comunicação e movimentos sociais, para as diferentes temporalidades e para a pluralidade de matrizes culturais" (p. 270). Tal alteração é sustentada pela incorporação do conceito gramsciano de hegemonia. $\mathrm{O}$ processo de dominação deixa de ser observado como algo vindo de um exterior, e passa a ser um processo consciente de influência direta de uma classe sobre a outra.

O grupo que recebe tal ação hegemônica tem como seus os valores em circulação, o que aponta o caráter relacional que a apropriação 
de sentidos passa a ter. Assim, as mediações, para Martín-Barbero (2001ª, p. 304), são "os lugares dos quais provêm as construções que delimitam e configuram a materialidade social e a expressividade cultural". Na prática educomunicacional elas interferem constantemente no processo de produção de sentidos.

Os lugares de mediação pensados por Martín-Barbero (2001a, p, 304-311) são a Cotidianidade Familiar, a Temporalidade Social e a Competência Cultural. A Cotidianidade Familiar, para o autor, é a "situação primordial de reconhecimento". Ela é um espaço de fortes tensões e conflitos, mas ainda assim um dos poucos lugares onde o sujeito é capaz de manifestar suas frustrações e ansiedades. Já a Temporalidade Social constitui-se como o espaço temporal contraposto ao tempo produtivo - são os intervalos, fragmentados e formado por pequenas unidades, comumente organizado pelas ofertas midiáticas. A última medicação proposta pelo autor é a Competência Cultural, ligada diretamente aos sistemas de consumo e as lógicas do sistema produtivo, assim como a experiências de vida do indivíduo.

Na obra "De los Medios a las Praticas" (1990), Martín-Barbero repensa as mediações anteriores e atualiza para três dimensões das práticas sociais, alterando os lugares de mediação. A primeira dimensão apontada pelo autor é a Sociabilidade, constituída por uma trama onde os atores sociais interagem e constroem suas identidades. Aqui, há as negociações de poder do sujeito com as instituições sociais. A Ritualidade é a segunda modalidade, caracterizada pelas rotinas de produção cultural e de significados. A última dimensão é a Tecnicidade, parte integrante dos processos comunicacionais e ligada diretamente aos meios.

É fundamental pensar neste componente especialmente pelas distintas formas de apropriações e criações de novas práticas sociais. A Sociabilidade como espaço de negociação é o palco das discussões fomentadas pela Educomunicação. A questão familiar, antes teorizada pela Cotidianidade Familiar, também ganha atenção pelo caráter de socialização. A Ritualidade liga-se diretamente a produções de sentido. Já a Tecnicidade se expressa através das falas que referenciam a influência das tecnologias e das mensagens por elas transmitidas.

Diante das múltiplas ofertas sociais e midiáticas, as ingerências das diferentes mediações é que proporcionam aos indivíduos constituíremse como sujeitos capazes de se expressar, analisar, interpretar, selecionar e se apropriar criticamente das mensagens que lhes convier para integrar sua experiência de vida e inserção no mundo.

Nesta perspectiva, as relações que se estabelecem são culturais, 
e é através da cultura que há relação, em uma simbiose. Segundo Freire (1977, p.65), "o homem, como um ser de relações, desafiado pela natureza, a transforma com o seu trabalho; e que o resultado final desta transformação, que se separa do homem, constitui seu mundo. $\mathrm{O}$ mundo da cultura que se prolonga no mundo da história". O "ser" torna-se humano, cultural e histórico através desta ação.

Essas relações culturais rompem a divisão entre "educador" "educando", produtor e receptor, que juntos aprendem, crescem e emancipamse. Neste processo, a Comunicação é o meio de relacionar multiculturas e sujeitos singulares entre si, com o outro e com o mundo "glocal". O ato de comunicar é capaz de promover a comunhão entre os seres, em uma ação problematizadora e dialógica. Martín-Barbero (2003, p. 38) complementa ao afirmar que "a palavra não se reduz a gesto, mas se inicia em, e por descobrimos que a linguagem não é tradução de ideias, mas uma forma de habitar o mundo, de fazer-se presente nele, de compartilhá-lo com outros homens".

Assim, o diálogo, que é encontro entre sujeitos singulares, transforma a construção de saber em experiência de "duração"; a Educação, em ação "permanente". Os valores variam, seguindo as mudanças culturais, todavia, o que permanece é a capacidade de crítica que é fomentada por essa Educação inclusiva e Comunicação libertadora, capaz de estimular mudanças, enquanto o contrário provoca "fobias sociais".

Através da Comunicação, o processo educacional não finda. Ele dissipa-se ao longo da existência de outros sujeitos, na prática dialógica. Desta forma, Freire (1976, p. 106) aponta a necessidade de uma "Pedagogia da Comunicação, com que vencêssemos o desamor acrítico do antidiálogo". Neste sentido, a Educomunicação pode ser uma alternativa na busca de espaços para a prática dialógica e a consolidação de uma cultura crítica, reflexiva e politizada.

\section{Educomunicação como Práxis Política e Multicultural}

A relação entre a Educação e a Comunicação mostra-se fundamental para a formação de sujeitos politizados e emancipados, capazes de pensar e agir criticamente sobre a realidade onde estão inseridos: desta relação, surge a Educomunicação. "O neologismo Educomunicação, que em princípio parece mera junção de Educação e Comunicação, na realidade, 
não apenas une as áreas, mas destaca de modo significativo um terceiro termo, a ação" (SOARES, 2009, p.2).

A Educomunicação coaduna com o caráter da teoria freiriana, visto que ambas pensam o diálogo e a ação comunicacional como fomentador do processo emancipatório. Segundo Freire (1976, p. 108), “o diálogo é, portanto, o indispensável caminho não somente nas questões vitais para nossa ordenação política, mas em todos os sentidos do nosso ser”. Problematizar a realidade torna-se palavra-chave para ambas, a fim de desvelar o mundo e dele apropriar conhecimentos e saberes.

A formulação do conceito de educomunicação perpassa características de ambas as áreas, fazendo jus ao caráter transdisciplinar que carrega. A Comunicação é o que transforma o ser humano em racional e o permite viver em grupos e organizações - ela é cultural. Assim, também a Educação o é, visto que o diálogo é pressuposto de uma Pedagogia Libertadora (FREIRE, 1976). Nessa visão, a Escola assumiria um papel de transformação social, abrindo espaço para a problematização e conscientização dos sujeitos no mundo "glocal" e midiatizado onde estão inseridos. Em uma sociedade que constantemente (re) significa suas práticas institucionais a escola ganha novos sentidos, valores e modos de ver, ser e estar na comunidade (MELO; TOSTA, 2008, p. 23). Neste contexto, surge o desafio do uso da mídia como fonte de educação informal, de novas mediações e formas de sociabilidade. Os autores (p. 24) sugerem que o educador "deve exercer seu papel de mediador na elaboração crítica e criativa de critérios de leitura das formas simbólicas ofertadas pelos meios de comunicação e tecnologias digitais".

Este esforço em prol de posturas críticas e emancipatórias perante as mensagens midiáticas integra os objetivos da Educomunicação. Ela também se caracteriza por ser mais do que um campo de conhecimento, sendo espaço de interação. Segundo Soares (2009, p.3), a Educomunicação é vista também como um campo de ação política, que reúne e estimula o debate sobre a diversidade de posturas, diferenças e possíveis semelhanças.

O objetivo maior não é o produto final em si, mas sim o desenvolvimento do processo. "Rico em detalhes, cheio de incongruências, ao mesmo tempo compreensível e difícil de entender, atraente, fascinante e pleno de problemas de toda a ordem" (SOARES, 2009, p.4). Um processo complexo e merecedor de atenção, dando à Educomunicação um caráter de prática, mas ao mesmo tempo sendo também um campo de entendimento discursivo. 
O contexto educomunicativo nos reporta ao conceito de práxis de Freire (2005, p. 15). A reflexão é vista como parte fundamental da práxis, capaz de relacionar diretamente teoria e prática. A crítica origina-se dentro da práxis, tornando-se parte dela e da existência de cada sujeito. A palavra, ponto fundamental e estímulo necessário ao diálogo, quando munida de reflexão, torna-se também ação. Nessa perspectiva, a ação e a vida são intimamente relacionadas e solidárias. "Mais que um puro fazer, é um quefazer, isto é, quando não se dicotomiza da reflexão" (2005, p. 44). O esclarecimento é parte da práxis, refletindo-se como a libertação dos sujeitados através do diálogo em relação as suas ações. A práxis, nesse cenário educomunicativo, é proposta de ação política - através dela que os sujeitos libertam-se de suas "prisões" e comprometem-se a uma nova perspectiva, com uma mudança pessoal.

A ação presente no processo educomunicativo possibilita que o indivíduo cresça e torne-se sujeito de si mesmo, capaz de novas leituras e apropriações das mensagens midiáticas, de novas ações como cidadão participativo. Neste sentido, Peruzzo aponta que

\begin{abstract}
A participação na Comunicação é um mecanismo facilitador da ampliação da cidadania, uma vez que possibilita a pessoa tornar-se sujeito de atividades de ação comunitária e dos meios de comunicação ali forjados, o que resulta num processo educativo, sem se estar nos bancos escolares (2002, p.7).
\end{abstract}

Deste modo, a Comunicação torna-se espaço de aprendizagem e reflexão, com destaque para o fazer comunicativo e sua prática de caráter educativo. Na visão de Peruzzo (2006, p. 10), os meios de comunicação podem contribuir para a Educação não apenas pelos conteúdos que transmitem, mas pelo processo de produção e difusão de mensagens que propiciam. Tal fala ratifica a importância e o significado que a participação dentro do processo comunicacional traz para a formação do sujeito. Também a consciência de si e do outro dentro do grupo social torna-se prerrogativa, visto que essa prática comunicativa dá subsídios a uma postura cidadã.

A prática educomunicacional trabalha uma relação de complementaridade entre o campo educacional e o midiático. $\mathrm{O}$ espaço de questionamento é ideal para a construção de e entre saberes, através de relações múltiplas entre o organizar de um saber formal (escola) e o estímulo a busca por mais conhecimento informal (mídia). 
Neste processo, os saberes são problematizados. As repetições de sensos comuns, preconceitos e pré-conceitos somente interessam por fomentar novos pensamentos e construções, básicas ao desenvolvimento de diferentes lugares e olhares - ou seja, o objetivo final é desconstruir o senso comum. Questionamentos e proposições levadas aos participantes estimulam novas posturas, com reflexos de autonomia, e novos discursos, carregados de novos significados.

O direito à palavra, assim como a produção comunicacional não é exclusiva daqueles que dominam certos saberes e técnicas. Ambos são pensados pela Educomunicação de forma compartilhada, sendo, para Soares (2009, p.5), “uma nova proposta de organização social”. Assim, a ação educomunicativa coaduna com os pensamentos de Freire $(1979,84)$, que concebe a educação como fruto de um jogo de contrários, sendo ação constante e de permanente "duração".

Portanto, a Educomunicação propõe uma ação política de cunho emancipatório, cuja afirmação como sujeito socialmente participativo é o resultado objetivado, por isso, "não aceitará nem o homem isolado do mundo - criando este em sua consciência - nem tampouco o mundo sem homem - incapaz de transformá-lo" (Freire, 1979, p.75). Por não estar sozinho no processo de aprendizado, formal e informal, a construção do conhecimento do sujeito depende diretamente da prática dialógica.

\section{Referências}

BELLONI, Maria Luiza. Mídia Educação. Campinas: Autores Associados, 2009.

DEMO, Pedro. Participação é Conquista. São Paulo: Cortez, 2009.

FREIRE, Paulo. Educação como Prática da Liberdade. Rio de Janeiro: Paz e Terra, 1976.

. Extensão ou Comunicação? . Rio de Janeiro: Paz e Terra, 1977.

. Educação e Mudança. Rio de Janeiro: Paz e Terra, 1979.

. Pedagogia do Oprimido . Rio de Janeiro/RJ: Terra e Paz, 2005.

- Pedagogia da Autonomia: saberes necessários à prática educativa. Rio de Janeiro: Paz e Terra, 1996.

KAPLÚN, Mario. De Medio y Fines em Comunicación. In: Chasqui-Re- 
vista Latinoamericana de Comunicación. S/a, no 58, 1997. Quito/Equador: Centro Internacional de Estudios Superiores de Comunicación para América Latina (CIESPAL), 1997.

. El Comunicador Popular. Ciespal: Quito, 1985.

MARTÍN-BARBERO, Jésus. Al Sur de la Modernidad. Pittsburgh: Instituto Internacional de Literatura Iberoamericana, Universidade de Pittsburgh, 2001b.

. Dos Meios às Mediações: Comunicação, Cultura e Hegemonia. Rio de Janeiro: Editora UFRJ, 2001a. 2003.

. La Educación desde la Comunicación. Bogotá: Grupo Editorial,

- Tecnicidades, Identidades, Alteridades: Mudanças e Opacidades da Comunicação no Novo Século. In: MORAES, Dênis de. Sociedade Midiatizada. Rio de Janeiro/RJ: Mauad, 2006.

MELO, José Marques de; TOSTA, Sandra Pereira. Midia e Educação. Belo Horizonte: Autêntica, 2008.

PERUZZO, Cicilia Maria Krohling. Comunicação Comunitária e Educação para a Cidadania. In: Pensamento Comunicacional Latino: Americano - Revista Digital. Volume 4, ano 1, 2002. Disponível em <http:// www2.metodista.br/unesco/PCLA/revista13/revista13.htm>. Acesso em 25/04/2010.

. Comunicação nos Movimentos Populares. Petrópolis: Vozes, 1998.

SOARES, Donizete. Educomunicação: O que é isto? Disponível em Portal GENS < http://portalgens.com.br/baixararquivos/textos/ educomunicacao_o_que_e_isto.pdf>. Publicado em 29/03/2009. Acesso em 27/04/10. 


\section{* Rosane Rosa}

Professora do POSCOM/

UFSM. Doutora em Comu-

nicação e Informação pela

UFRGS.

E-mail:

rosane.rosa@terra.com.br

** Manuela Ilha Silva

Mestrandra do POSCOM/

UFSM (ingresso 2011) e inte-

grante do Grupo de Estudos

"Comunicação, Educação e

Cidadania” (UFSM).

E-mail:

misilha@hotmail.com 